\title{
Frequency and Antibiotic Susceptibility of Pathogens from Cases of Urinary Tract Infection: A Prospective Observational Study
}

\author{
Gautam Ram Choudhary ${ }^{1}$ Pritesh Jain ${ }^{10}$ Himanshu Pandey ${ }^{1}$ Vijay Kumar Sarma Madduri ${ }^{1}$ \\ Mahendra Singh ${ }^{1}$ Prateek Gupta ${ }^{1}$ Suresh Goyal ${ }^{2}$ Vibhor Tak ${ }^{3}$ Vijaya Lakshmi Nag ${ }^{3}$ \\ ${ }^{1}$ Department of Urology, All India Institute of Medical Sciences, \\ Jodhpur, India \\ 2 Department of Urology, Guru Gobind Medical College, Faridkot, \\ Punjab, India \\ Address for correspondence Pritesh Jain, MS, M.Ch, DNB Urology, \\ Department of Urology, All India Institute of Medical Sciences, Basni \\ Industrial Area, Phase-2, Basni, Jodhpur, Rajasthan, 342005, India \\ (e-mail: drpriteshjain2010@gmail.com).
}

${ }^{3}$ Department of Microbiology, All India Institute of Medical Sciences, Jodhpur, India

J Lab Physicians 2022;14:265-270.

\begin{abstract}
Objectives Urinary tract infection (UTI) is one of the most common diagnoses in patients visiting urology clinics. Rampant use of empiric and inadequate doses of antibiotics leads to an increase in resistance and poses a huge financial burden. We evaluated UTI in relation to antibiotics used, frequency, susceptibility, and resistance pattern of different pathogens at a tertiary care center and made some important observations.

Methods Prospectively 729 patients diagnosed with UTI attending a urology outpatient department from July 2018 to January 2020 were managed accordingly. Antibiotics were started on the basis of urine culture and sensitivity $(c / s)$ or empirically and changed according to subsequent urine $\mathrm{c} / \mathrm{s}$. Repeat urine $\mathrm{c} / \mathrm{s}$ was performed after 5 to 7 days of starting therapy and 10 days after completion of therapy.

Results Out of 729 subjects, 417 (57.2\%) were males and $312(42.8 \%)$ were females. The most common symptom at diagnosis was dysuria 512 (70.2\%), whereas 221 (30.3\%) patients presented with fever. Escherichia coli was the most common organism isolated, 453 (62.1\%). Among 729 patients, 239 took antibiotics without c/s report, whereas in 490

Keywords

- antibiotic resistance

- antibiotics

- urinary tract infection patients antibiotics were prescribed after the report. A total of 431 (59.1\%) patients required one antibiotic session for clearance of pathogen, whereas $135(18.5 \%)$ required two sessions, and three sessions were required in $66(9 \%)$ cases. Among 239 patients whose culture came out to be positive, 145 (60.6\%) were found to be resistant to the previously
\end{abstract}

This study was carried out at the Department of Urology and Microbiology, All India Institute of Medical sciences, Jodhpur, Rajasthan, India. published online February 9, 2022
DOI https://doi.org/

$10.1055 / \mathrm{s}-0042-1742419$. ISSN 0974-2727. (c) 2022. The Indian Association of Laboratory Physicians. All rights reserved.

This is an open access article published by Thieme under the terms of the Creative Commons Attribution-NonDerivative-NonCommercial-License, permitting copying and reproduction so long as the original work is given appropriate credit. Contents may not be used for commercial purposes, or adapted, remixed, transformed or built upon. (https://creativecommons.org/ licenses/by-nc-nd/4.0/)

Thieme Medical and Scientific Publishers Pvt. Ltd., A-12, 2nd Floor, Sector 2, Noida-201301 UP, India 
given antibiotic and the common pathogens isolated were $E$. coli (61 [42\%]), Pseudomonas (28 [19.3\%]), Enterococcus (22 [15.1\%]), Klebsiella (14 [9.6\%]), and others.

Conclusion Unchecked, rampant, and inadequate use of antibiotics leads to complicated UTI with the increasing share of Pseudomonas, Klebsiella, or other dangerous microbes, which are difficult to treat as well as pose threat in the future.

\section{Introduction}

Urinary tract infection (UTI) is among the common infection in the community and health care settings. Their importance is related not only to how common they are but also to the significant morbidity they pose and the health care costs required in managing them. The goal is to eradicate the infection by selecting the appropriate antibiotics that would target specific bacterial susceptibility. There is increasing apprehension of widespread antimicrobial resistance owing to the prevalence of UTI and amount of antibiotics used in managing and preventing it. ${ }^{1,2}$

During these past years, there has been an upheaval of drug resistance among uropathogens, which has been shown to vary geographically. ${ }^{1,2}$ Several studies from various parts of the world have reported an increase in drug resistance trends among uropathogens. ${ }^{3,4}$ Such a trend can be evaluated using antibiograms from microbiology laboratory of hospitals in various localities. These antibiograms quantify drug resistance during a particular year and provide information regarding local antibiotic resistance among bacteria for a specific locale. ${ }^{5,6}$

The increasing frequency and spectrum of antimicrobialresistant UTIs in the hospitals and communities have been attributed to combinations of microbial characteristics, bacterial selection pressure caused by antimicrobial use, and societal and technologic changes that enhance the transmission of drug resistance. ${ }^{7}$

Antibiotic resistance has become a global problem, causing increased morbidity, mortality, and expenditure. ${ }^{3,8}$ For various classes of antibiotics, a relation between consumption and resistance has been documented in several studies. $^{9,10}$ It is imperative, therefore, that clinicians should be aware of changes in bacterial susceptibility and use current information while choosing antimicrobial agents.

The purpose of this study was to find out the frequency of the urinary pathogens isolated from the urine samples of patients with UTI and their antibiotic susceptibility pattern at a tertiary care hospital in Western India.

\section{Methods}

This prospective observational study complemented by retrospective data review that was conducted at a tertiary care center in India from July 2018 to January 2020. The study protocol was approved by the institutional ethics committee (Memo no. AIIMS/IEC/2018/051). The study procedure was in accordance with the principles of the Declaration of Helsinki. During this period all patients presenting to our outpatient department with symptoms suggestive of UTI were evaluated. Relevant history, examination, antibiotics given, urine culture sensitivity (c/s) reports, pathogens isolated, and antibiotic susceptibility of different pathogens to different antibiotics were compiled in a well-prepared chart. We included those patients who presented with symptoms suggestive of UTI like dysuria, urinary urgency, frequency, suprapubic discomfort with or without flank pain, fever, hematuria, etc. and they were evaluated and later diagnosed and treated for UTI based on c/s report.

Antibiotic that was either prescribed from outside or at our center was taken into account. At our center, those who had fever with chills, flank pain, etc. along with classical symptoms of UTI were empirically started on antibiotics at the first visit, after collection of urine samples for both microscopic analysis and culture sensitivity, while in other patients antibiotics were withheld until collection of the reports. We excluded patients with untreated urolithiasis, neurogenic bladder, chronic kidney disease, who received antibiotics within 6 months of the study, and who had foreign bodies in the urinary tract (ureteric stent, nephrostomy tube, etc.). Urine samples from patients were collected by a standard midstream clean catch method and in catheterized patients by inserting a needle into tubing by aseptic methods. Samples collected were examined microscopically and processed for culture and sensitivity. All the urine samples were processed using standard loop picking, $0.001 \mathrm{~mL}$ of urine to culture on UTI Hi chrome media. Significant colonies were processed by putting biochemicals for identification and antimicrobial susceptibility tests by the disc diffusion method.

Repeat culture was performed in patients showing contaminated or mixed growth in initial urine analysis. Standard criteria were used for interpretation of urine culture results as being significant and insignificant. Significant bacteriuria was considered when growth of more than or equal to 105 colony-forming units $/ \mathrm{mL}$ was obtained. ${ }^{11}$ The organism was identified by routine methods from the samples showing significant bacteriuria. ${ }^{12}$ According to the hospital policy, susceptibility of antibiotics was tested by the disc diffusion method for the first- and second-line antibiotics for which institution's own reference panel has been made using the CLSI (Clinical and Laboratory Standards Institute) M100-S30 document and current trends in local population. Second-line antibiotic susceptibility tests were used only if less than two susceptible antibiotics are therein first line. In female patients with uncomplicated UTI, antibiotics were prescribed for 3 to 5 days; in male patients and in female patients with structural or functional abnormalities of the 
genitourinary tract or the presence of an underlying disease other than from our exclusion criteria, minimum 7-day antibiotics were used. ${ }^{13}$. Repeat urine $\mathrm{c} / \mathrm{s}$ was performed after 5 to 7 days of starting antibiotics in all patients in next follow-up. In complicated UTI, repeat urine $\mathrm{c} / \mathrm{s}$ was done after 10 days of completion of antibiotic course. ${ }^{13}$ Full course of antibiotics was given according to current guidelines for complicated and uncomplicated UTI involving different urinary organs. For those patients who after completion of antibiotic course remained symptomatic or urine c/s at 5 to 7 days showed growth, antibiotics continued or changed according to clinical scenario.

The antibiotics tested were: for lactose fermenters (most common)-first line: amoxicillin, ciprofloxacin, levofloxacin, cotrimoxazole, ceftriaxone, fosfomycin, gentamicin, nitrofurantoin, tobramycin; second line: amikacin, colistin, ertapenem, meropenem, piperacillin-tazobactam, linezolid, and tigecycline with slight variations for other suspected strains.

Data were entered into Microsoft Excel and analyzed in reference to type of antibiotics given and sessions of antibiotics given for treatment of UTI. For each organism isolated by culture, mean susceptibility was calculated for antibiotics tested.

\section{Results}

In our study, total 945 patients were enrolled, out of them 216 were excluded as per exclusion criteria and 729 were included who presented with UTI symptoms and also had a positive urine culture. Out of these, 417 (57.2\%) patients were male and 312 (42.8\%) patients were female. For the ease of interpretation, we divided number of patients in different age categories. Among them, 37.1\% (272) patients were older than 60 years of age. The average age of our patients was $51 \pm 19.2$ years. - Table 1 shows demographic data of the patients.

Most patients presented with more than one symptom in the form of dysuria, frequency, urgency, fever, suprapubic discomfort, etc. (-Table 2). Dysuria was the most common symptom presenting in $512(70.23 \%)$ patients whereas 221 (30.31\%) patients presented with fever along with other symptoms of UTI.

Among 729 patients, 160 patients were diagnosed with UTI after recovery from some surgical intervention (other

Table 1 Distribution of data of patients diagnosed with urinary tract infection $(N=729)$.

\begin{tabular}{|l|l|l|l|}
\hline \multirow{2}{*}{ Age (in years) } & \multicolumn{2}{|l|}{ Gender } & \multirow{2}{*}{ Total } \\
\cline { 2 - 3 } & Male & Female & \\
\hline $0-10$ & 5 & 2 & $7(0.96 \%)$ \\
\hline $11-20$ & 8 & 21 & $29(3.9 \%)$ \\
\hline $21-40$ & 89 & 107 & $196(26.9 \%)$ \\
\hline $41-60$ & 153 & 73 & $226(31.0 \%)$ \\
\hline$>60$ & 162 & 110 & $272(37.1 \%)$ \\
\hline
\end{tabular}

Table 2 Distribution of the symptoms in cases with UTI.

\begin{tabular}{|l|l|l|}
\hline Clinical symptoms & Yes, $\boldsymbol{n}(\%)$ & No, $\boldsymbol{n}(\%)$ \\
\hline Fever & $221(30.3 \%)$ & $508(69.7 \%)$ \\
\hline Flank pain & $124(17.0 \%)$ & $605(83.0 \%)$ \\
\hline Dysuria & $512(70.2 \%)$ & $217(29.8 \%)$ \\
\hline Frequency & $451(61.9 \%)$ & $278(38.1 \%)$ \\
\hline Urgency & $145(19.9 \%)$ & $584(80.1 \%)$ \\
\hline Suprapubic pain & $215(29.5 \%)$ & $514(70.5 \%)$ \\
\hline $\begin{array}{l}\text { Others } \\
\text { (urethral discharge, } \\
\text { voiding LUTS, foul } \\
\text { smell in urine, } \\
\text { hematuria, etc.) }\end{array}$ & $136(18.6 \%)$ & $593(81.4 \%)$ \\
\hline Intervention required & $218(29.9 \%)$ & $511(70.1 \%)$ \\
\hline
\end{tabular}

Abbreviations: LUTS, lower urinary tract obstruction; UTI, urinary tract infection.

than entering into the urinary system) in last 3 weeks. A total of 218 (29.9\%) patients needed some form of intervention mostly urinary diversion in the form of per urethral catheterization/suprapubic catheterization/percutaneous nephrostomy/double-J stent placement. In total, 431 patients required only one antibiotic session for clearance of pathogen, 135 (18.5\%) required 2 sessions, and 3 sessions were required in 66 (9\%) cases. In 25 (3.4\%) patients even after five to six sessions of antibiotics, sterile urine was not reported. None of the patients died directly or indirectly due to UTI.

Out of total 729 patients with UTI, the most common organism isolated was Escherichia coli in 453 patients (62.1\%), followed by Enterococcus (95/13\%), Pseudomonas (78/10.7\%), and others. Among 490 patients who were started on antibiotics according to their urine $\mathrm{c} / \mathrm{s}$ report, repeat urine c/s revealed a different organism in 95 (19.4\%) patients and in them antibiotic was changed accordingly after completing full course of the initial antibiotic prescribed. Among these 239 patients who were previously treated empirically, urine c/s of 145 (62\%) reported resistance to already started antibiotic and common pathogens isolated in them were E. coli (61/42\%), followed by Pseudomonas (28/19.31\%), Enterococcus (22/15.1\%), Klebsiella (14/9.6\%), and others. Most common empirically started antibiotics were quinolones (105/43.4\%) and cephalosporins (76/31.8\%), and among those started after obtaining $\mathrm{c} / \mathrm{s}$ report were quinolones $(219 / 44.7 \%)$, followed by aminoglycosides (61/12.4\%), cephalosporins (58/11.8\%), and others ( - Table 3 ).

We also calculated the antibiotic susceptibility testing for commonly known uropathogens responsible for causing UTI. The data are provided in - Table 4. Among antibiotics, the highest mean susceptibility was found for piperacillin-tazobactam (48.5\%), followed by nitrofurantoin (45.7\%), ciprofloxacin (30\%), amikacin (28.14\%), and others in a decreasing order. Escherichia coli was most susceptible to piperacillintazobactam, followed by nitrofurantoin, levofloxacin, and others in a decreasing order. Pseudomonas was most 
Table 3 Pattern of antibiotics given to patients before urine culture and according to culture sensitivity report

\begin{tabular}{|l|l|l|l|}
\hline $\begin{array}{l}\text { Group of } \\
\text { antibiotics }\end{array}$ & $\begin{array}{l}\text { Antibiotic } \\
\text { given } \\
\text { without } \\
\text { urine culture } \\
\text { sensitivity, } \\
n(\%)\end{array}$ & $\begin{array}{l}\text { According to } \\
\text { urine culture } \\
\text { sensitivity, } \\
n(\%)\end{array}$ & Total \\
\hline Cephalosporins & $76(31.8)$ & $58(11.8)$ & $\begin{array}{l}134 \\
(18.4 \%)\end{array}$ \\
\hline $\begin{array}{l}\text { Macrolide } \\
\text { (azithromycin) }\end{array}$ & 0 & $22(0.2)$ & $22(3.0)$ \\
\hline Quinolones & $105(43.4)$ & $219(44.7)$ & $\begin{array}{l}324 \\
(44.4)\end{array}$ \\
\hline Sulfonamides & $10(4.2)$ & $48(9.7)$ & $58(7.9)$ \\
\hline Glycopeptides & 0 & $2(0.04)$ & $2(0.27)$ \\
\hline Aminoglycosides & $9(4.2)$ & $61(12.4)$ & $70(9.6)$ \\
\hline Carbapenems & $12(5.0)$ & $13(6.0)$ & $25(3.4)$ \\
\hline Penicillins & $8(2.7)$ & $17(3.4)$ & $25(3.4)$ \\
\hline Fosfomycin & 0 & $13(2.6)$ & $13(1.8)$ \\
\hline Nitrofurantoin & $19(7.9)$ & $37(7.5)$ & $56(7.7)$ \\
\hline
\end{tabular}

susceptible to piperacillin-tazobactam, followed by ciprofloxacin. Proteus was most susceptible to ciprofloxacin, followed by piperacillin-tazobactam (-Table 4 ).

\section{Discussion}

UTIs pose a major issue in patient care. UTI accounts for 3.5 to $9 \%$ of health-care-associated infections and their overall percentage ranges from 8.64 to $57.8 \%$ according to prevalence surveys. ${ }^{14,15}$ Type of pathogens isolated, antibiotics prescribed, and their resistance pattern differ regionally.

In the present study, the E. coli (62.1\%), Enterococcus faecalis (11.8\%), and Pseudomonas aeruginosa (10.5\%) were the most common pathogens isolated. In various welldesigned studies, E. coli was the most common pathogen isolated followed by other pathogens similar to our study. ${ }^{16,17}$ Escherichia coli, which was the principal pathogen isolated, showed high susceptibility to piperacillin-tazobactam, nitrofurantoin, levofloxacin, and others. Pseudomonas aeruginosa, which is a common cause of hospital-acquired UTI, was less sensitive to the common antibiotics but highly sensitive to piperacillin-tazobactam, ciprofloxacin, ceftazidime, and amoxicillin. Pseudomonas was susceptible to the second-line drugs and most of these are associated with high resistance to the first-line antibiotics used, namely, amoxicillin, amikacin, and others. This may be due to widespread clinical use of common antibiotics in the hospital and cross-resistance existing among various classes of antibiotics.

In our study, maximum susceptibility was shown to piperacillin-tazobactam followed by nitrofurantoin, cotrimoxazole, and others. The results of the present study showed that the mean susceptibility of the uropathogens was low for commonly used drugs like levofloxacin, ceftriaxone, etc.

In contrast to literatures, our study exhibits a higher number of males mostly above 60 years presenting with UTI than females in all age groups. ${ }^{18,19}$ This discrepancy may be due to the fact that males have more complicated and difficult-to-treat UTIs than females and being a tertiary care center most patients referred are males with complicated UTI.

In our study, $32.8 \%$ patients were administered antibiotics without $\mathrm{c} / \mathrm{s}$ before their visit to our center. We found a rise in appearance of Pseudomonas from 10.2 to $19.8 \%$ in urine c/s of patients who received inappropriate antibiotics without culture sensitivity reports. Futile use of antimicrobial agents without proper protocol doses and course leads to escalation of resistance to commonly used antibiotics. Besides, it also promotes unmasking of more resistant and difficult-to-treat pathogens like Pseudomonas and Klebsiella as can be seen in our study results.

Table 4 Table showing pathogens isolated and antibiotic susceptibility of different pathogens to different antibiotics

\begin{tabular}{|c|c|c|c|c|c|c|c|c|c|c|c|c|c|c|c|c|c|}
\hline \multirow{2}{*}{$\begin{array}{l}\text { Pathogen } \\
\text { isolated }\end{array}$} & \multirow{2}{*}{$\begin{array}{l}\text { No. }(\%), \\
N=729\end{array}$} & \multicolumn{16}{|c|}{ Antibiotic susceptibility (\%) } \\
\hline & & Amx & $\mathrm{Cfx}$ & Ppc & $\mathrm{Cmx}$ & $\mathrm{Nft}$ & Mpn & Amk & $\mathrm{Cfz}$ & Cps & Cpx & Lfx & Fos & Imp & Lzd & $\mathrm{Vcm}$ & $\mathrm{Col}$ \\
\hline $\begin{array}{l}\text { Escherichia } \\
\text { coli }\end{array}$ & $453(62.1)$ & 9.2 & 13.4 & 68.0 & 34.4 & 65.8 & 33.1 & 55.6 & 5.2 & 9.0 & 43.7 & 60.2 & 55.6 & 16.5 & 9.7 & 7.0 & 5.2 \\
\hline Klebsiella & $70(9.6)$ & 21.4 & 45.7 & 50.0 & 31.4 & 41.4 & 22.8 & 31.4 & 18.5 & 35.7 & 22.8 & 34.2 & 31.4 & 22.8 & 38.5 & 15.7 & 7.1 \\
\hline Pseudomonas & $77(10.5)$ & 27 & 16.9 & 57.1 & 15.6 & 9.0 & 27.2 & 15.5 & 29.9 & 3.9 & 36.4 & 11.7 & 15.5 & 18.1 & 19.4 & 1.2 & 9.0 \\
\hline Enterococcus & $86(11.8)$ & 86 & 6.9 & 15.1 & 13.9 & 93 & 12.7 & 36 & 12.8 & 16.2 & 12.8 & 13.9 & 36 & 12.7 & 51.1 & 19.7 & 3.5 \\
\hline Acinetobacter & $14(1.9)$ & 7.1 & 35.7 & 92.8 & 50.0 & 28.5 & 7.1 & 14.2 & 28.5 & 57 & 14.2 & 21.4 & 14.2 & 14.2 & 0 & - & - \\
\hline Staphylococcus & $12(1.6)$ & 16.6 & 8.3 & 25.0 & 58.3 & 66.7 & 8.3 & 8.3 & 15.1 & 8.3 & 16.7 & 8.3 & 8.3 & 8.3 & 8.3 & 8.3 & 8.3 \\
\hline Proteus & $11(1.5)$ & 27.2 & 27.2 & 54.5 & 27.2 & 18.1 & 18.1 & 36 & 45.4 & 18 & 63.6 & 36.3 & 36 & 18 & 9.0 & - & 9.0 \\
\hline $\begin{array}{l}\text { Mean } \\
\text { susceptibility }\end{array}$ & & 27.7 & 30.9 & 48.5 & 32.9 & 45.7 & 18.4 & 28.14 & 22.2 & 29.7 & 30.0 & 26.5 & 28.14 & 15.8 & 19.4 & 7.4 & 6.1 \\
\hline
\end{tabular}

Abbreviations: Amk, amikacin; Amx, amoxicillin; Cfx, ceftriaxone; Cfz, ceftazidime; Cmx, cotrimoxazole; Cps, cefoperazone sulbactam; Cpx, ciprofloxacin; Fos, fosfomycin; Imp, imipenem; Lfx, levofloxacin; Lzd, linezolid; Mpn, meropenem; Nft, nitrofurantoin; Ppc, piperacillin; Vcm, vancomycin; Col, colistin. 
Antibiotic resistance is inevitably also affected by national wealth. There are proper guidelines and clinical pathways developed by high-income countries to guide in optimal use of antibiotics. They often have extensive surveillance systems to monitor antibiotic use and resistance. ${ }^{20-22}$

In contrast, antibiotic surveillance in low-income countries is challenging but urgent. It may generate valuable information for public health interventions. Since most countries in Asia are of developing cadre, they do not have any surveillance system to monitor unrestrained use of antibiotics leading to higher rates of resistance in Asia. ${ }^{23,24}$ Nevertheless, many Asian countries have now instituted antibiotic stewardship programs to regulate antibiotic usage. Among the risk factors for antibiotic-resistant pathogens, antibiotic usage is identified to be most important reason for its acquisition. Stewardship program regulating and monitoring use has decreased the levels of $E$. coli resistance to the applicable antibiotics. ${ }^{25}$ However, choosing the appropriate antimicrobial agents is often difficult as many antibiotics are available, and the length of therapy and lowest effective dose are not well defined.

Our study has its own limitations, for example, small sample size, single-institution study, and improper documentation of urine $\mathrm{c} / \mathrm{s}$ reports and antibiotics prescribed in few patients. Hence, it should be interpreted with circumspection.

\section{Conclusion}

An increasing proportion of Pseudomonas and Klebsiella were detected on repeat urine culture reports especially in empirically treated patients. These pathogens were also found resistant to commonly used antibiotics. The urge and pressure to treat patients as fast as possible compelling the treating physician to use high-order antibiotics as first line without accurate diagnosis and investigation of UTI patients have landed us in predicament. Critical measures are required to regulate antimicrobial use with the provision of local hospital antibiograms to prevent this surge of antibiotic resistance. Clinicians can then incorporate such protocols and manage UTI without any confusion.

\section{Conflict of Interest}

None declared.

\section{References}

1 Manges AR, Johnson JR, Foxman B, O’Bryan TT, Fullerton KE, Riley LW. Widespread distribution of urinary tract infections caused by a multidrug-resistant Escherichia coli clonal group. N Engl J Med 2001;345(14):1007-1013

2 World Health Organization. Global action plan on antimicrobial resistance. 2015. Accessed March 20, 2019: http://www.who.int/antimicrobial-resistance/publications/global-action-plan/en/

3 Mazzulli T. Antimicrobial resistance trends in common urinary pathogens. Can J Urol 2001;8(Suppl 1):2-5

4 Alam MF, Cohen D, Butler C, et al. The additional costs of antibiotics and re-consultations for antibiotic-resistant Escherichia coli urinary tract infections managed in general practice. Int $\mathrm{J}$ Antimicrob Agents 2009;33(03):255-257
5 Kibret M, Abera B. Prevalence and antibiogram of bacterial isolates from urinary tract infections at Dessie Health Research Laboratory, Ethiopia. Asian Pac J Trop Biomed 2014;4(02): 164-168

6 Bahadin J, Teo SSH, Mathew S. Aetiology of community-acquired urinary tract infection and antimicrobial susceptibility patterns of uropathogens isolated. Singapore Med J 2011;52(06):415-420

7 Shepherd AK, Pottinger PS. Management of urinary tract infections in the era of increasing antimicrobial resistance. Med Clin North Am 2013;97(04):737-757, xii

8 Shlaes DM, Gerding DN, John JF, et al. Society for Healthcare Epidemiology of America and Infectious Diseases Society of America Joint Committee on the Prevention of Antimicrobial Resistance: guidelines for the prevention of antimicrobial resistance in hospitals. Clin Infect Dis 1997;25(03):584-599

9 Goossens H. Antibiotic consumption and link to resistance. Clin Microbiol Infect 2009;15(Suppl 3):12-15

10 Costelloe C, Metcalfe C, Lovering A, Mant D, Hay AD. Effect of antibiotic prescribing in primary care on antimicrobial resistance in individual patients: systematic review and meta-analysis. BMJ 2010;340:c2096

11 Lammers RL, Gibson S, Kovacs D, Sears W, Strachan G. Comparison of test characteristics of urine dipstick and urinalysis at various test cutoff points. Ann Emerg Med 2001;38(05):505-512

12 Cruickshank R, Duguid JP, Marnian BP, Swain RH. Tests for identification of bacteria. In: Cruickshank R, ed,. Medical Microbiology, Vol II, 12th ELBS ed. London: Churchill Livingstone; 1975: 170-189

13 Schaeffer AJ, Schaeffer EM. Infections of the urinary tract. In: Wein AJ, Kavoussi LR, Partin AW, Peters CA, eds. Campbell-Walsh Urology, 10th ed. Philadelphia, PA: WB, Saunders company; 2012:297-300

14 Smyth ET, Mcllvenny G, Enstone JE, et al; Hospital Infection Society Prevalence Survey Steering Group. Four country healthcare associated infection prevalence survey 2006: overview of the results. J Hosp Infect 2008;69(03):230-248

15 Xie DS, Xiong W, Xiang LL, et al. Point prevalence surveys of healthcare-associated infection in 13 hospitals in Hubei Province, China, 2007-2008. J Hosp Infect 2010;76(02):150-155

16 Tandogdu Z, Cek M, Wagenlehner F, et al. Resistance patterns of nosocomial urinary tract infections in urology departments: 8year results of the global prevalence of infections in urology study. World J Urol 2014;32(03):791-801

17 Choe HS, Lee SJ, Cho YH, et al; GPIU Asian Investigators. Aspects of urinary tract infections and antimicrobial resistance in hospitalized urology patients in Asia: 10-Year results of the Global Prevalence Study of Infections in Urology (GPIU). J Infect Chemother 2018;24(04):278-283

18 Chu CM, Lowder JL. Diagnosis and treatment of urinary tract infections across age groups. Am J Obstet Gynecol 2018;219(01): 40-51

19 Wagenlehner FME, Cloutier DJ, Komirenko AS, et al; EPIC Study Group. Once-daily plazomicin for complicated urinary tract infections. N Engl J Med 2019;380(08):729-740

20 Mölstad S, Erntell M, Hanberger H, et al. Sustained reduction of antibiotic use and low bacterial resistance: 10-year follow-up of the Swedish Strama programme. Lancet Infect Dis 2008;8(02): $125-132$

21 Lim JM, Singh SR, Duong MC, Legido-Quigley H, Hsu LY, Tam CC. Impact of national interventions to promote responsible antibiotic use: a systematic review. J Antimicrob Chemother 2020;75 (01):14-29

22 Moet GJ, Jones RN, Biedenbach DJ, Stilwell MG, Fritsche TR. Contemporary causes of skin and soft tissue infections in North America, Latin America, and Europe: report from the SENTRY Antimicrobial Surveillance Program (1998-2004). Diagn Microbiol Infect Dis 2007;57(01):7-13

23 Chandy SJ, Thomas K, Mathai E, Antonisamy B, Holloway KA, Stalsby Lundborg C. Patterns of antibiotic use in the community 
270 Urinary Tract Infection: Trends and Challenges Choudhary et al.

and challenges of antibiotic surveillance in a lower-middle-income country setting: a repeated cross-sectional study in Vellore, South India. J Antimicrob Chemother 2013;68(01):229-236

24 Howard P, Pulcini C, Levy Hara G, et al; ESCMID Study Group for Antimicrobial Policies (ESGAP) ISC Group on Antimicrobial Stewardship. An international cross-sectional survey of antimicrobial stewardship programmes in hospitals. J Antimicrob Chemother 2015;70(04):1245-1255

25 Boel J, Andreasen V, Jarløv JO, et al. Impact of antibiotic restriction on resistance levels of Escherichia coli: a controlled interrupted time series study of a hospital-wide antibiotic stewardship programme. J Antimicrob Chemother 2016;71(07):2047-2051 